\title{
Budget emphasizes industry-driven research
}

$\mathrm{T}$ he 2015 federal budget promises more than $\$ 1.5$ billion for research and development over the next five years, but offers little for discovery-driven science, focusing instead on industry and market priorities.

The new money - much of it to arrive after the 2015/16 fiscal year includes $\$ 1.33$ billion over six years for the Canada Foundation for Innovation, beginning in 2017/18. But there are no new funds for the three federal granting agencies this year.

Starting in 2016/17, the Canadian Institutes of Health Research (CIHR), the Natural Sciences and Engineering Research Council of Canada (NSERC) and the Social Sciences and Humanities Research Council (SSHRC) will divide $\$ 35$ million in new funds, with an additional $\$ 9$ million for the indirect costs of research. The granting council funds are highly directed at industry-driven research.

Of the \$15 million NSERC will receive, $\$ 10$ million is for collaborations with companies and colleges and universities for research in natural resources and energy, advanced manufacturing, environment and agriculture. The other $\$ 5$ million is for industrydriven research projects at polytechnics and colleges.

The additional \$7 million that SSHRC will receive is also earmarked for partnerships among academic, business and other research partners for projects involving knowledge translation.

Included in the CIHR's additional $\$ 15$ million, is $\$ 13$ million to expand its Strategy for Patient-Oriented Research "to advance health care innovation in partnership with provincial governments, research institutions and the private and not-for-profit sectors." Only \$2 million per year will go to basic research at CIHR, focusing on antibiotic-resistant infections.

The new investments are intended to build on Canada's success in "attracting the best and brightest minds from around the globe in science, research

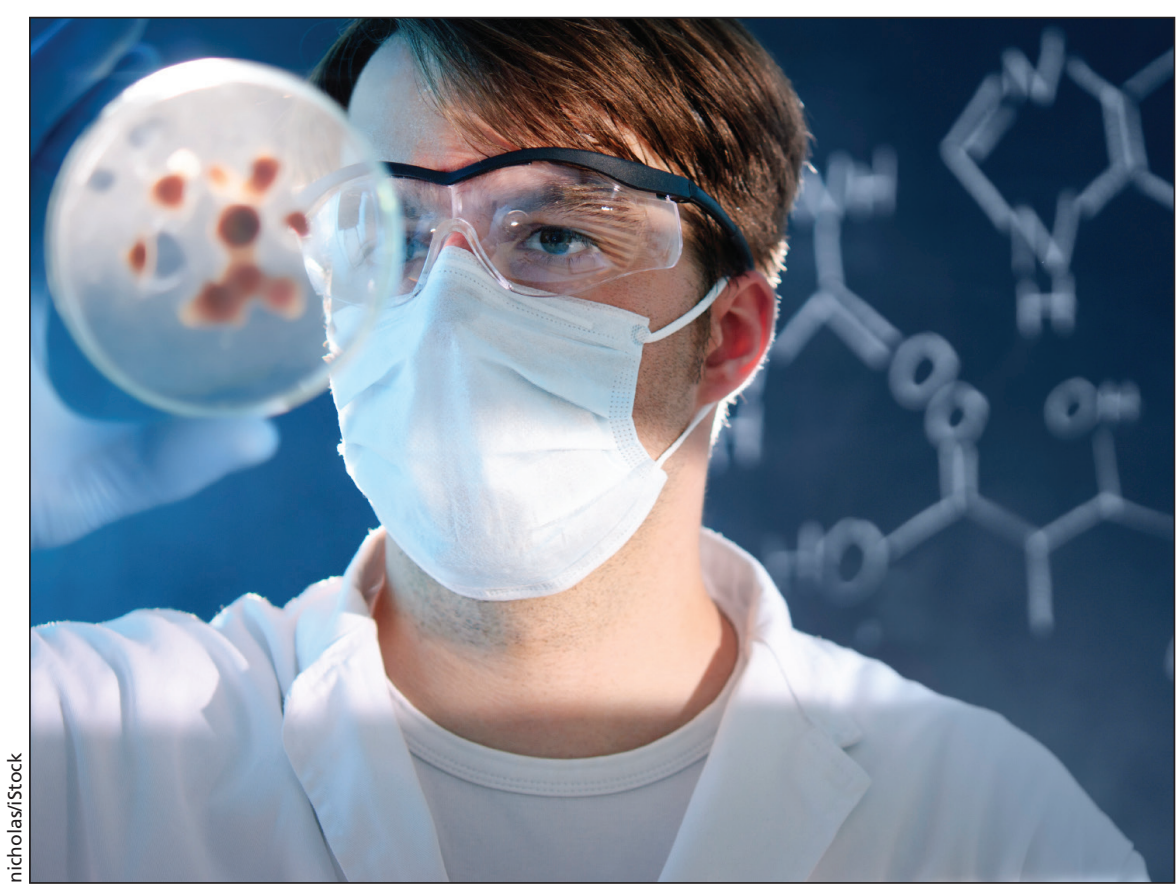

The federal government needs a more balanced approach to funding research say critics of this year's budget.

and development," Finance Minister Joe Oliver told the House of Commons in tabling the April 21 budget.

Although the country's largest postsecondary sector groups such as the Association of Universities and Colleges of Canada praised the budget's research and development funding, they were conspicuously silent about the lack of new money for the granting councils. Other groups were less restrained.

"When it comes to supporting university-based research, the federal government has an unbalanced approach," David Robinson, the executive director of the Canadian Association of University Teachers, said in a statement. "This budget, by directing new funding to specific industry-related projects, confirms this. The government continues to miss the fact that real innovation and scientific advancements are driven by long-term basic research, not shortterm market demands."

The government made "critical investments" in research and develop- ment (R\&D) in Canada, but it also missed an opportunity to support the health innovation system by spreading its support across the entire continuum of research, said Deborah GordonEl-Bihbety, president and CEO of Research Canada.

The federal government is focused on commercialization and translation of research, which is important, but that is only the front-end of the innovation continuum, says Gordon-El-Bihbety, whose organization represents an alliance of research institutes, hospitals, universities and health charities.

"You have to invest in discovery research as well as develop those commercialization programs," she told CMAJ in an interview. The research community must do a better job of conveying that message, she says, and of educating MPs about the length of time it takes for basic research to generate results.

One of the organizations that will see money flowing this year - the National Research Council - will get $\$ 119.2$ million over two years to sup- 
port R\&D partnerships with industry. Another, the CANARIE high-speed research network, will get $\$ 105$ million over five years for international research collaborations and to provide small business owners and entrepreneurs with access to cloud resources.

A close analysis of the research investments by Higher Education Strategy Associates, a Toronto-based consultancy firm, contends that compared to previous years' investments, this budget is not doing enough to bolster Canada's desire to be a global leader in competing for world-class students and scholars.

The investment in the Canada Foundation for Innovation looks impressive, the group points out, but "at an average of \$222 million in new funding per year, this is substantially below the 1997-2012 average of $\$ 370$ million per year in funding. This will make it difficult for Canada to maintain its position as a research leader in areas such as science, engineering, and medicine," the analysis says.

The budget also provides $\$ 243.5$ million over 10 years to ensure Canadian participation in the Thirty Meter Telescope at the Mauna Kea volcano in Hawaii; \$45 million over five years for TRIUMF, the world's largest cyclotron particle accelerator in Vancouver; and Atomic Energy of Canada Ltd. will receive $\$ 72.3$ million to continue to operate the nuclear reactors at its Chalk River
Laboratories safely, although they are being phased out of production.

Beginning in 2016/17, Ottawa will also allocate $\$ 56.4$ million over four years to support 6000 graduate research and development internships at Mitacs, a non-profit organization supporting applied and industrial research partnerships with governments and businesses.

The budget gave the Council of Canadian Academies, an independent evidence-based research body, an unexpected gift of $\$ 15$ million over five years to renew its mandate. The council had feared it might not be renewed. Laura Eggertson, Ottawa, Ont.

CMAJ 2015. DOI:10.1503/cmaj.109-5048 